\title{
Hereditary neuropathy with liability to pressure palsy: fulminant development with axonal loss during military training
}

\author{
S H Horowitz, L E Spollen, W Yu
}

J Neurol Neurosurg Psychiatry 2004;75:1629-1631. doi: 10.1136/innp.2003.029314

Hereditary neuropathy with liability to pressure palsy (HNPP) is characterised by recurrent mononeuropathies following minor trauma. We describe a case of fulminant HNPP beginning on the first day of military physical training. Protracted weakness, muscle atrophy, hand contractures, and multifocal sensory loss developed during a further three weeks of basic training. Nerve conduction changes were typical of HNPP, but without segmental slowing. Electromyographically, there was prominent acute denervation in muscles of the hands and right shoulder. Sural nerve biopsy demonstrated tomaculae and remyelination. Genetic testing revealed PMP-22 gene deletion. This case report demonstrates that HNPP can present with rapidly progressive peripheral nerve dysfunction and electrophysiological evidence of focal axonal loss.

$\mathrm{H}$ ereditary neuropathy with liability to pressure palsy (HNPP) is an autosomal dominant disorder with episodic recurrent mononeuropathies consequent to minor trauma or compression. There are five or six presenting phenotypes $^{12}$; in the commonest compressive form complete or almost complete recovery after each event is typical. ${ }^{2}$ Electrophysiological studies demonstrate prolonged distal motor latencies (DML), normal or mildly reduced motor and sensory conduction velocities (CVs), prolonged f-wave latencies, reduced sensory nerve action potential (SNAP) amplitudes, and segmental slowing at usual sites of compression-for example, the ulnar nerve at the elbow and the peroneal nerve at the fibular head. ${ }^{1-4}$ Nerve biopsy shows recurrent demyelination and myelin reduplication resulting in formation of tomaculae $e^{5}$ and reduction in axonal diameter. ${ }^{6}$ Genetic studies show a 1.5 megabase deletion on chromosome 17pl1.2-12 bearing the peripheral myelin protein $22(P M P-22)$ gene. $^{8}$

We report a patient with HNPP who was asymptomatic until beginning military physical training; with continued strenuous activity she developed significant disabilities, pronounced muscle atrophy, and electrophysiological evidence of focal acute axonal damage.

\section{CASE REPORT}

A 21 year old white woman in good health, who had recently passed a US Army physical examination, on her first day of military training developed foot numbness while wearing combat boots and hand numbness and weakness while doing 150 push-ups and carrying a $34 \mathrm{~kg}$ backpack for 20 minutes. She continued the strenuous training for another three weeks, despite developing severe pain, weakness, and atrophy in her right shoulder, and bilateral hand muscle weakness and atrophy with contractures, such that personal hygiene and grasping of simple objects were seriously impaired. She was not taking any medication, denied toxin exposure and use of illicit drugs, tobacco, or alcohol. Her mother and her family had no history of neuromuscular disease. She did not know her father or his family history.

She was admitted to a local hospital where a magnetic resonance imaging (MRI) scan of the brain and cervical spine, and cerebrospinal fluid, electrophysiological, immunological, and neurotoxic evaluations were normal. She was diagnosed as having atypical peripheral neuropathy of either chronic inflammatory demyelinating or multifocal type. She was given intravenous methylprednisolone but there was no improvement.

Our examination, eight weeks after onset, revealed the following abnormalities on muscle testing (Medical Research Council Scale, 0-5): orbicularis oculi, 3 bilaterally; neck extensors, 4; neck flexors, 5; right deltoid, 2; left deltoid, 4; right supraspinatus and infraspinatus, 1, with severe atrophy; left supraspinatus and infraspinatus, 4; bilateral biceps, brachioradialis and left triceps, 5-; right triceps, 3; right wrist and finger extensors, 3; left wrist and finger extensors, 4; finger flexors, 5 bilaterally; all intrinsic muscles of both hands and both abductor pollicis brevi, 0 -trace, with marked atrophy and early flexion contractures producing claw hands. Lower extremity strength was entirely normal; she could walk on her toes and heels and do multiple deep knee bends. She had a flattened smile and normal bulbar muscle and tongue strength.

The deep tendon reflexes (DTRs) were absent at both triceps, reduced at both biceps and brachioradialis muscles, and normal in the lower extremities. There were glove and stocking sensory deficits to all modalities at the ankles and wrists, and decreased pin and touch sensations of both upper extremities, neck and torso down to T7, and in both V2 and V3 trigeminal distributions. Sensation was normal over V1 distributions, back of the head, and the torso below T7 down the lower extremities to the ankles. Before making the final diagnosis, a five day course of intravenous immunoglobulin ( $400 \mathrm{mg} / \mathrm{kg}$ per day) was administered but without effect.

She had multiple follow up examinations, and on the last, one year after onset of symptoms, there was minimal improvement in intrinsic hand muscle function, with continued atrophy and clawing. There was no improvement in her right shoulder muscle strength or atrophy. Weakness in the lower extremity muscles was first noted on the three month examination. She could not perform one deep knee bend nor walk on her heels. Bilaterally, the iliopsoas muscles

Abbreviations: CMT1, Charcot-Marie-Tooth disease type 1; CV, conduction velocities; DML, distal motor latencies; DTR, deep tendon reflex; HNPP, hereditary neuropathy with liability to pressure palsy; MAP, motor action potential; PMP-22, peripheral myelin protein 22; SNAP, sensory nerve action potential 
were 4; quadriceps, 3; and anterior compartment muscles 3. Lower extremity DTRs remained normal. At one year she regained some lower extremity strength in that she could perform a few deep knee bends, but fatigued easily when walking $1 \mathrm{~km}$.

Motor and sensory conduction studies of nerves of the right upper and lower extremities (table 1) disclosed nonuniform slowing of motor and sensory CVs; prolonged DMLs in all nerves except the tibial; markedly reduced (ulnar nerve) or absent (suprascapular) motor action potential (MAP) amplitudes while other MAP amplitudes were normal; reduced SNAP amplitudes in all but one nerve (sural); and prolonged or absent (ulnar) f-wave latencies. Slowing of median nerve conduction across the carpal tunnel was confirmed with palmar stimulation studies. It was notable that there was no segmental slowing of ulnar nerve conduction across the elbow or of peroneal nerve conduction across the fibular head.

Electromyography of muscles of all four extremities revealed profound acute denervation in muscles innervated by both brachial plexuses and the right suprascapular nerve (both first dorsal interossei, right abductor digiti minimi, right abductor pollicis brevis, right supraspinatus and infraspinatus, right deltoid), whereas other muscles were minimally affected or normal. There was no evidence of chronic denervation.

The right sural nerve was biopsied using standard methods. Teased fibre analysis revealed a striking increase in the percentage of fibres with segmental demyelination/

Table 1 Results of the nerve conduction study

\begin{tabular}{|c|c|c|}
\hline \multirow[b]{2}{*}{ Nerve } & \multicolumn{2}{|l|}{ Values } \\
\hline & Normal & Patient's* \\
\hline \multicolumn{3}{|l|}{ Right median nerve } \\
\hline Motor latency, wrist & $<4.2 \mathrm{~ms}$ & 6.5 \\
\hline Motor CV, forearm & $>45 \mathrm{~m} / \mathrm{s}$ & 47.8 \\
\hline MAP amplitude & $>4 \mathrm{mV}$ & 6.2 \\
\hline F-wave latency & $<28 \mathrm{~ms}$ & 33.6 \\
\hline Sensory CV, wrist & $>45 \mathrm{~m} / \mathrm{s}$ & 28.8 \\
\hline SNAP amplitude & $>19 \mu v$ & 14 \\
\hline \multicolumn{3}{|l|}{ Right ulnar nerve } \\
\hline Motor latency, wrist & $<3.5 \mathrm{~ms}$ & 7.7 \\
\hline Motor CV, forearm & $>49 \mathrm{~m} / \mathrm{s}$ & 59.2 \\
\hline Motor CV, elbow & $>45 \mathrm{mV}$ & 57.1 \\
\hline MAP amplitude & $>3 \mathrm{~ms}$ & 0.23 \\
\hline F-wave latency & $<28 \mathrm{~ms}$ & NR \\
\hline Sensory CV, wrist & $>44 \mathrm{~m} / \mathrm{s}$ & NR \\
\hline SNAP amplitude & $>18 \mu \mathrm{v}$ & NR \\
\hline \multicolumn{3}{|l|}{ Right radial nerve } \\
\hline Sensory CV, wrist & $>45 \mathrm{~m} / \mathrm{s}$ & 44.8 \\
\hline SNAP amplitude & $>12 \mu \mathrm{v}$ & 5 \\
\hline \multicolumn{3}{|l|}{ Right suprascapular nerve } \\
\hline Motor latency, shoulder & $<3.7 \mathrm{~ms}$ & NR \\
\hline MAP amplitude & $>3 \mathrm{mv}$ & NR \\
\hline \multicolumn{3}{|l|}{ Right peroneal nerve } \\
\hline Motor latency, ankle & $<5.5 \mathrm{~ms}$ & 6.9 \\
\hline Motor CV, leg & $>40 \mathrm{~m} / \mathrm{s}$ & 39.4 \\
\hline Motor CV, knee & $>40 \mathrm{mv}$ & 34.5 \\
\hline MAP amplitude & $>2.5 \mathrm{~ms}$ & 8.1 \\
\hline F-wave latency & $<52 \mathrm{~ms}$ & 62.5 \\
\hline Sensory CV, wrist & $>45 \mathrm{~m} / \mathrm{s}$ & 27.0 \\
\hline SNAP amplitude & $>8 \mu \mathrm{v}$ & 4 \\
\hline \multicolumn{3}{|l|}{ Right tibial neve } \\
\hline Motor latency, ankle & $<6.0 \mathrm{~m} / \mathrm{s}$ & 5 \\
\hline Motor CV, leg & $>41 \mathrm{mV}$ & 41 \\
\hline MAP amplitude & $>2.9 \mathrm{~ms}$ & 9 \\
\hline F-wave latency & $<55 \mathrm{~ms}$ & 58.8 \\
\hline \multicolumn{3}{|l|}{ Right sural nerve } \\
\hline Sensory CV, leg & $>40 \mathrm{~m} / \mathrm{s}$ & 37.8 \\
\hline SNAP amplitude & $>12 \mu v$ & 15 \\
\hline
\end{tabular}

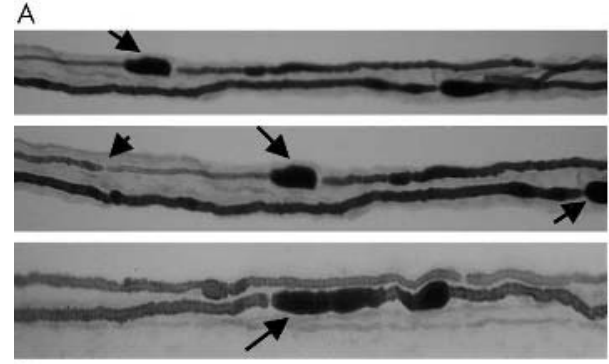

B

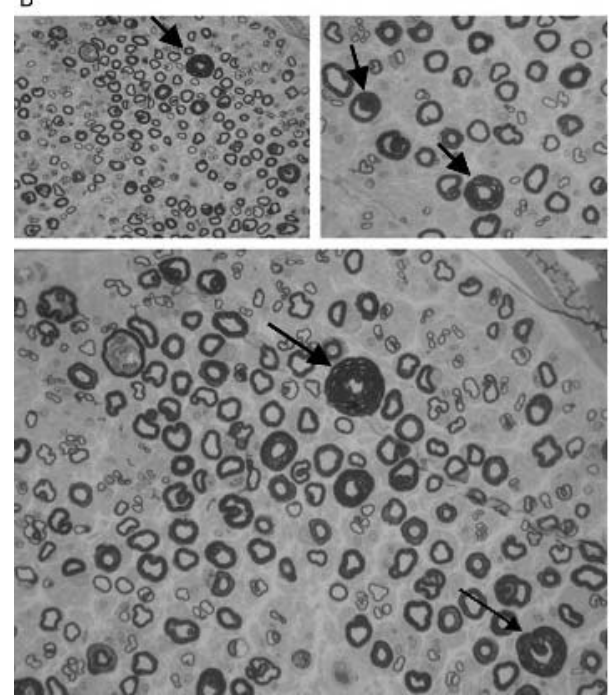

Figure 1 (A) Teased fibre preparation of the right sural nerve showing focal sausage shaped enlargements of the myelin sheath (tomaculae) (indicated by solid arrows) and thinly remyelinated internodes (indicated by arrow head). (B) Epon section of sural nerve demonstrating marked variation in myelin thickness and several large hypermyelinated axons (indicated by solid arrows).

remyelination (35\%). Sausage shaped swellings occurred in $45 \%$ of the fibres, usually paranodal (fig lA). These tomaculae varied in length from $87 \mu \mathrm{m}$ to $230 \mu \mathrm{m}$. Thirty four per cent of fibres showed both changes. Some fibres showed acute axonal degeneration (7\%).

Transverse Epon sections demonstrated marked variation in myelin thickness and several large hypermyelinated axons. Fibre density was normal. Occasional hypermyelinated fibres were scattered throughout each fascicle, visible at low magnification $(\times 10)$ (fig 1B, upper panel). Fibre enlargement was due to a markedly thickened myelin sheath, usually surrounding an atrophic axon, confirmed by electron microscopy. Numerous thinly myelinated axons, indicating remyelination, were noted.

Step sections of the biopsy did not reveal plasma cells or lymphocytes in nerve, vessel, or adjacent tissues. There were a few scattered macrophages (CD68+) in the perivascular spaces and soft tissues surrounding the nerve. CD20 stain for $\mathrm{B}$ lymphocytes was negative. CD3 stain for $\mathrm{T}$ lymphocytes showed only rare positive cells.

Genetic testing by restriction endonuclease digestion and Southern blot analysis (Athena Diagnostics, Worcester, MA) demonstrated PMP-22 deletion at chromosome 17p11.2-12.

\section{DISCUSSION}

This patient, with pathological and genetic confirmation of HNPP, presented with bilateral brachial plexus and right suprascapular nerve neuropathies secondary to strenuous physical activity. Further clinical and electrophysiological investigations revealed widespread neuropathic dysfunction, 
including bilateral facial paresis. An extensive work up for immunological, infectious, or neurotoxic causes was unrevealing. Spontaneous or hereditary neuralgic amyotrophy, another diagnostic consideration, was eliminated by the widespread clinical distribution, sensory loss, and genetic findings.

This patient's manifestation of HNPP is unique in its fulminant onset, focal axonal dysfunction, and protracted clinical course with severe deficits persisting one year after onset. She did not have the cardinal features of $\mathrm{HNPP}^{12}{ }^{9}$ : autosomal dominant inheritance and recurrent mononeuropathy simplex or multiplex related to trivial trauma or compression, nor did she match any of the less common forms described by Kumar et al and Mouton et al. ${ }^{2}$ Additionally, most patients with HNPP have a benign clinical course; Mouton et al ${ }^{2}$ reported that only $15 \%$ of patients with the common form of HNPP have significant residual weakness. A few earlier reports have documented fulminant onset, claw hand deformity, "moderate fibrillation potentials" (one patient), ${ }^{10}$ or acute denervation activity in isolated muscles (two patients), ${ }^{7}$ or focal brachial plexus involvement with acute denervation activity as the sole manifestation of HNPP (one patient). ${ }^{11}$ However, each of these patients experienced full recovery within a few months.

While the presentation and severity of this patient's condition may relate to a specific unknown genetic profile with very low PMP-22 mRNA levels, Schenone et al, ${ }^{6}$ in finding correlations between reduced PMP-22 mRNA levels and disease severity, also suggested that extrinsic factorsfor example, level of physical activity, may be important in determining phenotypic features. This appears to be true of our patient-that she was neurologically normal, then developed symptoms on the first day of military physical training with progression as she continued the training over a three week period, suggests that disease severity and focal axonal damage were related to these intense activities. Additionally, as it has recently been recognised that sporadic cases of HNPP are common, ${ }^{2}{ }^{12}$ either because of de novo mutations or asymptomatic carriers, her lack of family history did not preclude this diagnosis. She did not know her father or his family and her mother refused examination.

Although the genetic defect in HNPP results in abnormal peripheral nerve myelin, this patient's clinical and electrophysiological findings suggest that PMP-22 deletion can be associated with axonal damage, as is the PMP-22 duplication in Charcot-Marie-Tooth disease type 1 (CMTl). Her axonal damage was acute, related to mechanical factors brought on by intense physical activity, and focal, in the distribution of the medial cords of both brachial plexus and the right suprascapular nerve (the limited axonal damage on sural nerve biopsy supports the focality of this condition). Axonal dysfunction in CMTl is chronic, generalised, and symmetric with little electrophysiologic evidence for acute denervation.
We conclude that HNPP is more common and its presentation more varied than currently thought. HNPP should be considered in patients presenting with rapidly progressive neuropathic dysfunction, perhaps related to intense physical activity, especially if asymmetric, even with clinical and neurophysiological evidence of axonal loss. It should be noted that this patient's complaints were repeatedly dismissed or ignored at her military base; she was considered a malingerer. Earlier recognition of the significance of her nascent symptoms would have led to an earlier diagnosis of HNPP and limited the severity of her impairments.

\section{Authors' affiliations}

S H Horowitz, W Yu, Division of Neurology, University of Missouri

School of Medicine, Columbia, MO, USA

L E Spollen, Department of Pathology, University of Missouri School of Medicine, Columbia, MO, USA

Competing interests: none declared

Correspondence to: S H Horowitz, MD, Division of Neurology, M-178, University of Missouri School of Medicine; Columbia, MO 65212, USA; horowitzs@health.missouri.edu

Received 29 September 2003

In revised form 20 January 2004

Accepted 11 February 2004

\section{REFERENCES}

1 Kumar NJ, Cole J, Parry GJ. Variability of presentation in hereditary neuropathy with liability to pressure palsy results in underrecognition. Ann N Y Acad Sci 1999;883:344-50.

2 Mouton P, Tardieu S, Gouider R, et al. Spectrum of clinical and electrophysiologic features in HNPP patients with the $17 \mathrm{p} 11.2$ deletion. Neurology 1999:52:1440-6.

3 Andersson PB, Yuen E, Parko K, et al. Electrodiagnostic features of hereditary neuropathy with liability to pressure palsies. Neurology 2000;54:40-4.

4 Li J, Krajewski K, Shy ME, et al. Hereditary neuropathy with liability to pressure palsy: the electrophysiology fits the name. Neurology 2002:58:1769-73.

5 Madrid R, Bradley WG. The pathology of neuropathies with focal thickening of the myelin sheath (tomaculous neuropathy), studies on the formation of the abnormal myelin sheath. J Neurol Sci 1975;25:415-48.

6 Schenone A, Nobbio L, Caponnetto C, et al. Correlation between PMP-22 messenger RNA expression and phenotype in hereditary neuropathy with liability to pressure palsies. Ann Neurol 1997;42:866-72.

7 Behse F, Buchthal F, Carlsen F, et al. Hereditary neuropathy with liability to pressure palsies: electrophysiological and histopathological aspects. Brain 1972:95:777-94.

8 Chance PF, Alderson MK, Leppig KA, et al. DNA deletion associated with hereditary neuropathy with liability to pressure palsies. Cell 1993;72:143-51. 9 Meier C, Moll C. Hereditary neuropathy with liability to pressure palsies: report of two families and review of the literature. J Neurol 1982;228:73-95.

10 Crum BA, Sorenson EJ, Abad GA, et al. Fulminant case of hereditary neuropathy with liability to pressure palsy. Muscle Nerve 2000;23:979-83.

11 Orstavik K, Heier MS, Young P, et al. Brachial plexus involvement as the only expression of hereditary neuropathy with liability to pressure palsies. Muscle Nerve 2001;24:1093-6.

12 Infante J, Garcia A, Combarros O, et al. Diagnostic strategy for familial and sporadic cases of neuropathy associated with $17 \mathrm{p} 11.2$ deletion. Muscle Nerve $2001 ; 24: 1149-55$. 